Research Article

\title{
Experimental and Numerical Investigation of Hard Rock Breakage by Indenter Impact
}

\author{
Hongxiang Jiang $\mathbb{D}^{1,2,3}{ }^{1,2}$ Zhiyuan Cai ${ }^{D},{ }^{1}$ Ouguo Wang, ${ }^{1}$ and Deguang Meng ${ }^{1}$ \\ ${ }^{1}$ School of Mechatronic Engineering, China University of Mining and Technology, Xuzhou 221116, China \\ ${ }^{2}$ Jiangsu Engineering Technology Research Center on Intelligent Equipment for Fully Mining and Excavating, \\ China University of Mining and Technology, Xuzhou 221008, China \\ ${ }^{3}$ Jiangsu Collaborative Innovation Center of Intelligent Mining Equipment, China University of Mining and Technology, \\ Xuzhou 221008, China
}

Correspondence should be addressed to Hongxiang Jiang; jianghongxiang@cumt.edu.cn and Zhiyuan Cai; ts18050089p31@cumt.edu.cn

Received 23 January 2020; Revised 27 April 2020; Accepted 6 May 2020; Published 18 May 2020

Academic Editor: Evgeny Petrov

Copyright (C) 2020 Hongxiang Jiang et al. This is an open access article distributed under the Creative Commons Attribution License, which permits unrestricted use, distribution, and reproduction in any medium, provided the original work is properly cited.

To investigate the effect of indenter shape, impact energy, and impact velocity on the rock breakage performance, a test device for rock fragmentation by indenter impact was developed to obtain the rock breakage volume, depth, and area under different impact conditions. By comparing the rock breakage volume, depth, area, and specific energy consumption, the results show that indenter shape has a greater influence on the rock breakage performance than that of the impact velocity with the same impact energy, and impact energy plays a decisive role in rock breakage performance with an identical indenter shape and impact velocity. For the lowest to highest specific energy consumption, the order of indenter shape is cusp-conical, warhead, hemispherical, spherical-arc, and flat-top under the same impact energy and velocity, but the cusp-conical indenter is damaged after several impacts. The rock breakage volume, depth, and area all increase with the increase in impact energy, but the effect of the impact velocity could be ignored under the same impact energy. In addition, the rock breakage features of the numerical simulation and experiments are similar, which show that the crushing zone close to the indenter impact point is mainly caused by the high compressive stress, and then radial cracks are caused by the accumulative energy release. The findings of this study will contribute to progress in the performance and efficiency for percussive rock drilling.

\section{Introduction}

Many methods have been used for coal and rock excavation, including mechanical tools, high-pressure water jets, microwaves, and thermal methods [1-4]. The percussive drilling method is commonly used in tunneling and mining and is still the fundamental process for hard rock excavation $[5,6]$. The difficulty and inefficiency of hard rock drilling is a bottleneck for hard rock excavation, and the rock breakage ability of the mechanical indenter directly determines the formation efficiency of hard rock holes. The rock drilling efficiency, specific energy consumption, and indenter service life are all related to the rock properties, impact energy, and indenter shape. Many scholars have investigated the rock breakage performance of mechanical bits, such as indenter wear and force and rock fragmentation efficiency.

The rock fragmentation processes by means of single and double indenters were investigated through a numerical method [7], and it was concluded that the confining pressure and line space for the double indenters have an important influence on the rock breakage performance. Kou et al. [8] used the tool interaction code to simulate the rock breakage under the action of a drill bit and revealed the mechanisms of crack initiation, propagation, and coalescence under button indenter impact. Liu et al. [9] obtained a better understanding of the rock breakage mechanism by means of the button indenter using the tool interaction code, and a formula was established to identify the optimum line space 
based on the rock properties and button-indenter parameters. Huang and Detournay [10] revealed that the action of a tool can induce either ductile and/or brittle failure through rock indentation and cutting experiments and found that the brittle mode presented the propagation of cracks. Saksala [11-13] investigated the bit-rock interaction process by means of a developed numerical model based on viscoplasticity and isotropic damage, confirmed that the present numerical model accurately predicted the experimental craters, and indicated that the hydrostatic pressure and confining pressure had a sizeable effect on the percussive drilling of hard rocks. Hashiba et al. [14] investigated the impact penetration behavior of the button indenter in laboratory tests and found that the peak force, initial slope, and elastic penetration increased while the maximum and final penetrations decreased with an increase in the secant slope. Lundberg and Collet [15] pursued an optimal incident wave for maximizing the efficiency of the conversion of wave energy into rock breakage under indenter impact. Fourmeau et al. [16] presented experimental and numerical research on rock breakage by a multi-indenter bit and found that the confining pressure has an effect of an approximately $10 \%$ decrease in the rock breakage volume. Aziznejad et al. [17] adopted the distinct element code (PFC2D) to investigate the rock fracture under impact loading, and the numerical results are very consistent with the experiments. Cinca et al. [18] evaluated the behavior of three cemented carbide grades used for oil and gas applications under microscale impact fatigue, and the highest fatigue sensitivity was found for the grade with lower contiguity and a higher mean free path.

However, there are fewer investigations on the hard rock breakage performance due to different indenter shapes, energies, and velocities through experiments, and most of the previous studies focused on rock fragmentation processes and numerical modeling. To investigate the effect of the indenter shape and the impact parameters on the rock fragmentation extent, a test device for rock breakage by indenter impact was developed to obtain the rock breakage volume, depth, and area under different impact conditions. Based on the developed test device and corresponding numerical model, the following topics were researched: (a) the hard rock breakage process, including crushing zone formation and crack propagation, was investigated by comparing the rock crushing zone size and crack distribution; (b) the rock breakage features, including the crushing zone and rock debris, were compared and analyzed under different indenter shapes; (c) the rock fragmentation diameter, depth, volume, and specific energy consumption were obtained under different indenter shapes, impact velocities, and energies based on the developed test device; (d) the effect laws of indenter shape, impact velocity, and energy on rock breakage performance were put forward, and a better indenter shape was recommended.

\section{Methods}

2.1. Experimental Device. The influence factors on rock breaking performance by means of indenter impact mainly include the impact energy, final velocity of the impact hammer (instantaneous velocity of the impact hammer when the impact hammer collides with the drilling bit), and indenter shape, while the observation and recording parameters mainly include the rock breakage volume, diameter, and depth. Specific energy consumption is a comprehensive evaluation index for rock fragmentation, which can be calculated according to the rock breakage volume and impact energy. As shown in Figure 1, the test device for rock breakage by means of indenter impact is composed of a guider, lifting device, impact hammer, drilling bit, base support, location height, and indenter. The rock breakage test procedure is as follows: (a) place the hard rock on the base support; (b) select an impact hammer with a given weight; (c) choose and install an indenter in the drill bit; (d) lift the impact hammer by the lifting device to a given height according to the location marks (holes); (e) release the lifting device and the impact hammer will fall freely along the guider; and (f) the collision between the impact hammer and drill bit results in rock breakage by the indenter. The main parameters of the experimental device are listed in Table 1.

\subsection{Experimental Parameters and Rock Breakage} Performance. It is difficult to use a speed sensor or highspeed camera to obtain the final velocity of the impact hammer with regard to the rock breakage test device because there is a large impact with vibrations as well as high-speed debris in the rock breaking process. Considering the structure and characteristics of the test device, as shown in Figure 1, the final velocity of the impact hammer can be conveniently obtained, and the measurement accuracy is satisfactory. The motion of a free falling body is used to measure and calculate the final velocity of the impact hammer. In the test device, the impact energy is transformed from the gravitational potential energy when the impact hammer falls freely from the initial height to the bit position.

In rock breakage by means of indenter impact, the indenter assembled in the drilling bit has an important influence on the rock fragmentation performance, and the effect of the indenter shape on rock breakage is still unclear. Thus, it is necessary to investigate rock breakage by means of indenters with different shapes. The indenter shapes used in the test mainly include the cusp-conical, warhead, hemispherical, spherical-arc, and flat-top shape, as shown in Figure 2, and all the diameters of the different indenters are equal to $12 \mathrm{~mm}$. In addition, the material of the indenters is conventional cemented carbide [19].

According to the location height $h$ and mass $m$, the impact energy velocities are equal to $m g h$ and $\sqrt{2 g h}$, respectively. Then, we can identify the different impact energies and velocities by lifting the impact hammer to a specific height. Furthermore, a greater impact energy can be obtained by changing the mass of the impact hammer.

In these experiments, the rock breakage volume, diameter (diameter of the breakage area), depth, and specific energy consumption were calculated and analyzed to estimate the rock fragmentation performance. The rock crushing volume was measured by the gravel backfilling 


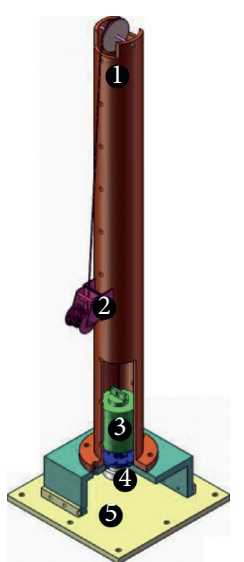

(1) Guider

(2) Lifting device

3) Impact hammer

(4) Drilling bit
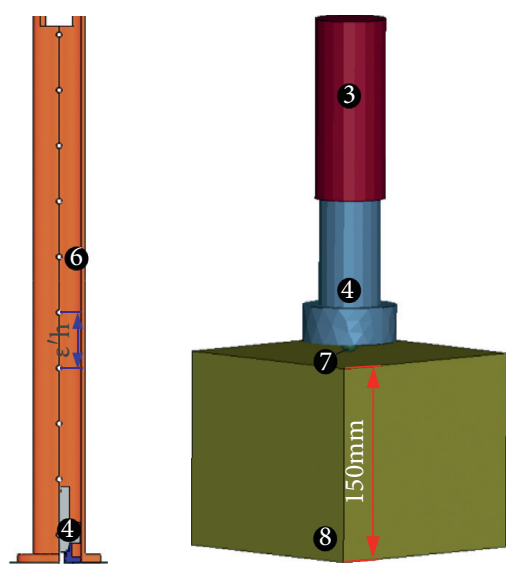

(5) Base support

(6) Location height

(7) Indenter

(8) Hard rock

FIgURE 1: Test device for rock breakage by indenter impact.

Table 1: Parameters of the experimental device.

\begin{tabular}{lc}
\hline Parameters & Height \\
\hline Value & 2000 \\
\hline &
\end{tabular}

(a)

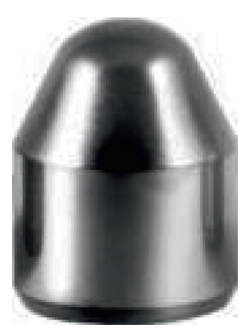

(b)

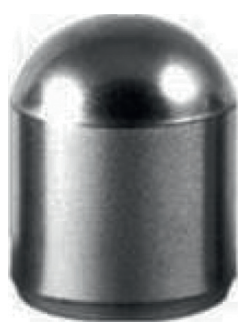

(c)

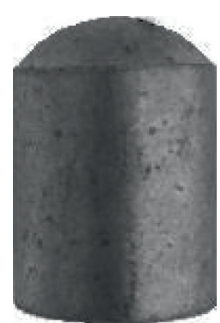

(d)

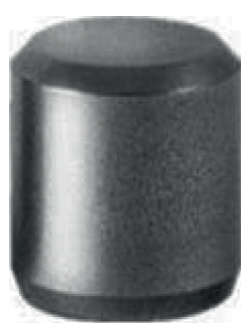

(e)

FIGURE 2: Shape of different indenters: (a) cusp-conical, (b) warhead, (c) hemispherical, (d) spherical-arc, and (e) flat-top.

method. The particles of gravel are uniform and fine, as shown in Figure 3, which can reduce the measurement error. The rock fragmentation diameter was approximatively measured with a steel ruler as shown in Figure 4, and the rock breakage depth was measured by a vernier caliper. The specific energy consumption is a comprehensive evaluation index for the rock fragmentation index [20], which can be calculated according to the impact energy and rock breakage volume [21]:

$$
\mathrm{SE}=\frac{E}{V},
$$

where SE is the specific energy consumption of the rock breakage, $\mathrm{J} / \mathrm{cm}^{3}$; $E$ is the impact energy, J; and $V$ represents the rock fragmentation volume, $\mathrm{cm}^{3}$.

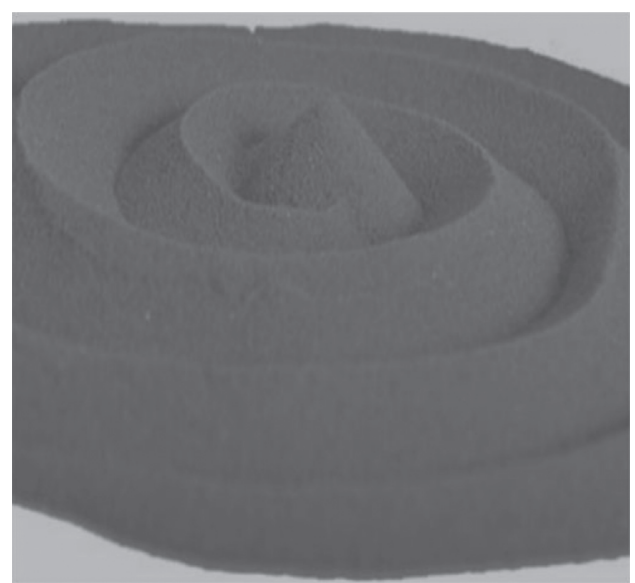

Figure 3: Gravel used for the volume measurement. 


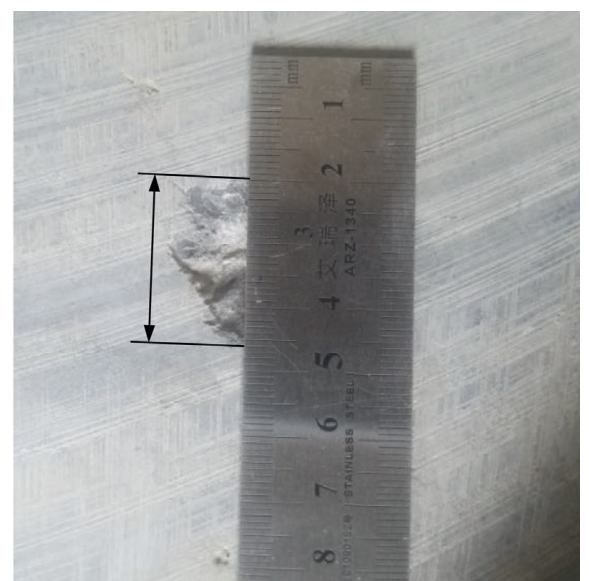

FIgURE 4: Measurement of the rock breakage diameter.

2.3. Mechanical Properties of Rock. According to the testing standard, we prepared two kinds of test specimens for obtaining the rock properties: the rock with a height of $100 \mathrm{~mm}$ and a diameter of $50 \mathrm{~mm}$ is used to evaluate the uniaxial compressive strength; the rock with a thickness of $25 \mathrm{~mm}$ and a diameter of $50 \mathrm{~mm}$ is adopted to obtain the tensile strength. The uniaxial compression test and Brazilian disc test were carried out using the powerful electronic test machine [22]. The rock elastic modulus, Poisson's ratio, uniaxial compressive strength, and tensile strength are obtained from the standard mechanical test, and the density can be calculated according to the mass and volume of the rock specimen. The rock failure features by means of the uniaxial compression test and Brazilian disc test are shown in Figure 5, and the mechanical properties of the bluestone are listed in Table 2.

\section{Numerical Rock Breakage}

First, a numerical method was adopted to investigate the rock breakage mechanism, and a numerical model of the rock fragmentation by indenter impact was established according to Figure 1. The material of the impact hammer and drill bit was $45 \#$ steel, and the indenter material was cemented carbide. The constitutive model of the RHT (Riedel-Hiermaier-Thoma) was used to describe the mechanical response and damage of bluestone because it has successfully simulated brittle material fragmentation for materials such as coal, rock, and concrete [23-25]. When the impact energy, initial impact velocity, and hammer weight are equal to $278.3 \mathrm{~J}, 5.33 \mathrm{~m} / \mathrm{s}$, and $20 \mathrm{~kg}$, respectively, the rock breakage statuses at different times by the hemispherical indenter impact are shown in Figure 6. Due to the impact interaction between the indenter and hard rock, a great pressure will be produced, such as high-speed liquid and projectile impact $[26,27]$. Because of the large pressure, the stress states of the rock under the indenter impact quickly reach the failure surface, and the element damage accumulates in the wake of the plastic strain [2]. This is why the rock near the indenter impact point is damaged at a time of $0.35 \mu \mathrm{s}$, as shown in Figure 6(a), and the red color (damage reached to 1) indicates complete failure of the hard rock constituting the crushing zone due to the shear stress. Meanwhile, there are several symmetrical crack formations with respect to the direction of indenter impact, and these phenomena appear as a result of the rock continuity and isotropy, which have no effect on the rock failure behavior and mechanism $[26,28]$. With the process of indenter advancement, the crack propagation and rock crushing zone all enlarge when the time reaches $0.73 \mu \mathrm{s}$, as shown in Figure 6(b). At this moment, a radial crack such as the Hertz crack appears around the rock crushing zone $[8,29]$, which may be caused by the interaction between the rock and indenter with a small impact speed. When the time reaches $1.9 \mu \mathrm{s}$, more radial cracks are produced and propagate to damage the internal rock, as shown in Figure 6(c), which is beneficial for rock breakage by the subsequent indenter impact. In addition, although the diameter of the crushing zone and the cumulative length of the cracks all increase compared with those of rock at a time of $0.73 \mu \mathrm{s}$, the depth of the rock crushing zone is almost unchanged, which indicates that the indenter with a low impact speed mainly promotes propagation and enlarges the diameter of the crushing zone at the end of the impact. Different from the time of $0.35 \mu \mathrm{s}$ and $0.73 \mu \mathrm{s}$, there are several transverse cracks at the time of $1.9 \mu \mathrm{s}$, which is caused by the release of the crushing zone or the compressive stress transitioning to tensile stress at the unloading stage. As shown in Figure 6(d), the rock will not fail in compression when the indenter is in a stage of unloading; the rock crushing zone is almost unchanged compared with that of Figure 6(c); however, the cumulative length and propagation depth of the cracks increase significantly. Thus, we can conclude that the loading and unloading stages are mainly for the crushing zone and radial and transverse crack propagation [30]. Generally, the radial cracks propagating into the inside of the rock will damage the rock, and some of the radial cracks propagate and become parallel to the top surface of the rock due to the free boundary and stress wave reflection $[31,32]$.

The same impact energy and velocity are adopted in the experiments based on the test device for the rock breakage by indenter impact, as shown in Figure 1; the rock fragmentation features and crack distribution are presented in Figure 7 and are consistent with typical rock failure due to impact [33]. The diameter of the rock crushing zone in the numerical simulation and experiment is $41.3 \mathrm{~mm}$ and $39 \mathrm{~mm}$, respectively, and the error for the depth of the rock crushing zone between these two methods is only $5.2 \%$, which indicates that the numerical model can commendably simulate rock crushing. In addition, the crack distribution is basically consistent with that in Figure 6, which confirms the capacity of the developed numerical model for simulating crack propagation. However, the density of the radial cracks obtained in the experimental test is significantly higher than that of the cracks in the numerical simulation, which is mainly due to the existence of flaws and weak interfaces in the natural rock [34]. When the natural rock is subjected to an external load, the flaws and weak interfaces are more likely to experience stress concentrations and failure, which directly results in the development of crack initiation and 


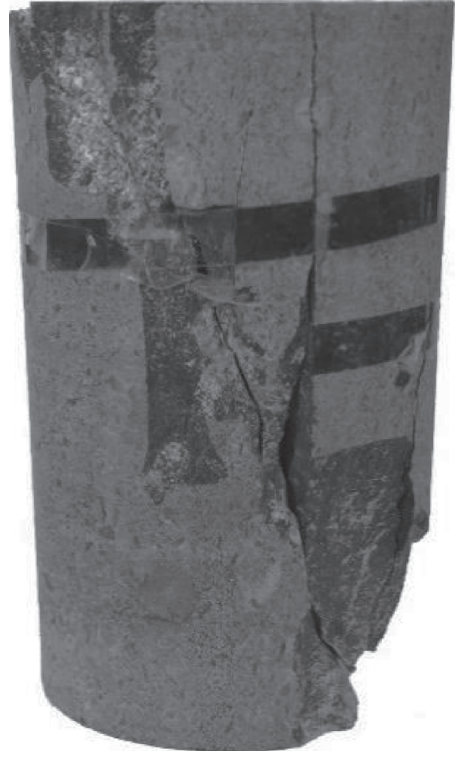

(a)

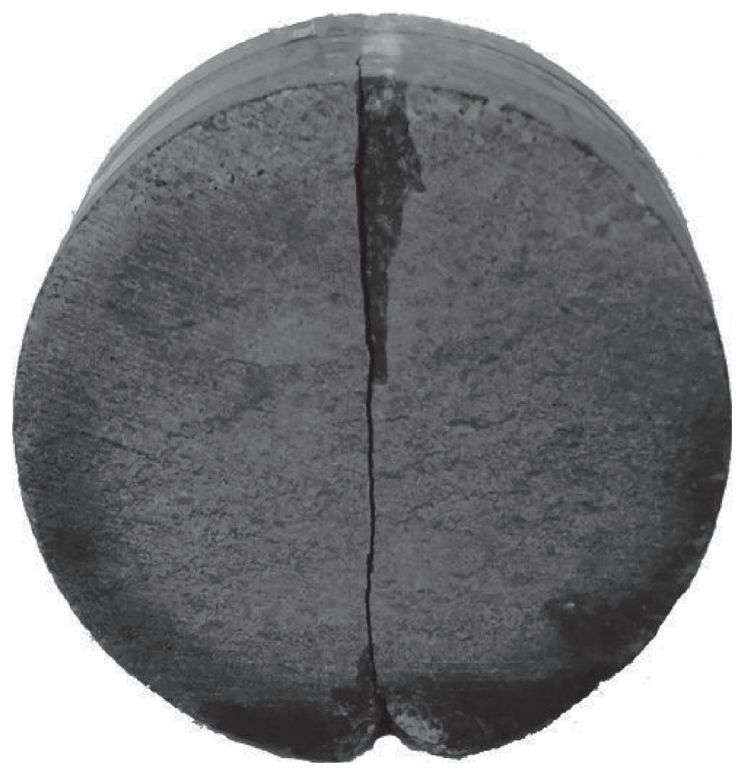

(b)

Figure 5: Rock failure features under the uniaxial compression test and Brazilian disc test. (a) Compression failure. (b) Tension failure.

TABLE 2: Mechanical properties of the bluestone.

Rock specimen Compressive strength $\sigma_{\mathrm{c}}(\mathrm{MPa})$ Modulus of elasticity $E(\mathrm{GPa})$ Poisson's ratio $\mu$ Tensile strength $T(\mathrm{MPa})$ Density $\rho$

\begin{tabular}{llcccc}
\hline Bluestone & 122.2 & 46.3 & 0.27 & 9.50 & $2.6 \mathrm{~g} / \mathrm{cm}^{3}$
\end{tabular}

propagation in the rock under indenter impact. According to the rock breakage status of the numerical simulation and the experiment from Figures 6(d) and 7, the microscopical rock breakage depth is smaller than that of the depth of the crushing zone from the numerical simulation and experiment, but the weakened rock can be broken easily by the next indenter impact.

\section{Influencing Factors of Rock Breakage}

4.1. Rock Breakage Features under Different Indenter Shapes. The indenter shape has a great influence on the rock breakage; thus, five types of indenters are used in the rock breakage, as shown in Figure 2. When the impact energy and velocity are equal to $278.3 \mathrm{~J}$ and $5.33 \mathrm{~m} / \mathrm{s}$, respectively, the rock fragmentation statuses after the indenter impact with different indenter shapes are shown in Figure 8. On the macrolevel, the rock can be broken with debris formation by the indenter types of the cusp-conical, warhead, hemispherical, and spherical-arc shape, as shown in Figures 8(a)$8(\mathrm{~d})$, but the rock fragmentation extent is different. It is worth noting that it is difficult to break the hard rock by means of a flat-top indenter under this condition, as shown in Figure 8(e). After clearing the debris, the boundaries of the rock fragmentation are shown in Figure 9, and the dense core formations are under the impact points. Noticeably, the dense cores are all circular from an aerial perspective with different indenter shapes except for the core of the flat-top indenter test, but the boundary curves of the rock fragmentation are noncircular and dissimilar because of the different interaction statuses between the rock and indenter as well as the rock anisotropy. According to Figure 8, a larger amount of rock debris can be obtained by the indenter shape types of the cusp-conical, warhead, and hemispherical shapes, which are better than those of the spherical-arc and flat-top indenter shapes. The rock breakage extent by different indenter shapes can provide a basis for the rock breakage by multi-indenter impacts. Interestingly, the rock breakage boundary for the hemispherical and spherical-arc indenters is closer to a circle; thus, we may conclude that the contact stability between the rock and the hemispherical and spherical-arc indenters is better than that of the cusp-conical and warhead shape indenters.

\subsection{Rock Breakage Performance under Different Indenter} Shapes. To estimate the rock breakage performance, the rock breakage volume, diameter (diameter of the breakage area), depth, and specific energy consumption are calculated and analyzed under different indenter shapes. The effect of the indenter shape on the rock breakage volume is shown in Figure 10. The rock breakage volumes under the cuspconical, warhead, and hemispherical indenters are all larger than those of the spherical-arc and flat-top shapes. As a whole, the rock breakage volumes by these indenters all increase with increasing impact energy, and the increasing rate of the rock breakage volume also increases with a larger impact energy over $200 \mathrm{~J}$. From the perspective of the rock breakage depth, it is also affected by the indenter shape, and the order of the indenter shapes for larger rock breakage depth is cusp-conical, warhead, hemispherical, sphericalarc, and flat-top shapes under the same impact energy and velocity for the lowest to highest rock breakage depth, as shown in Figure 11. Under the different indenter shapes, the 


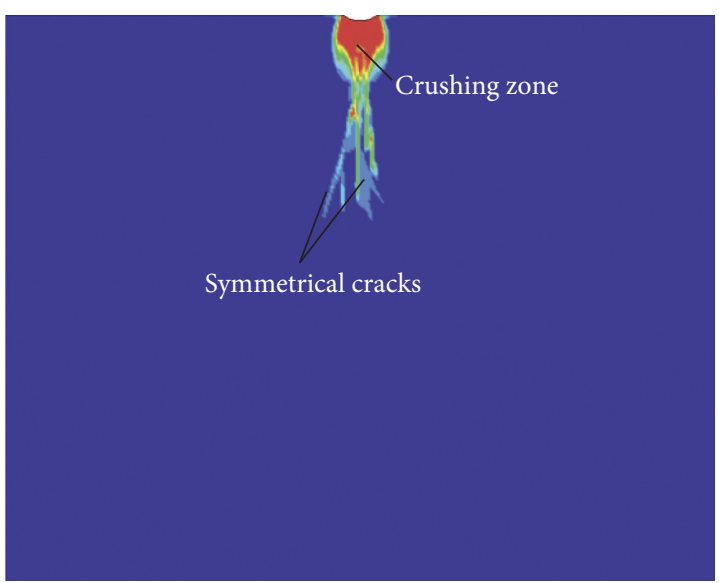

(a)

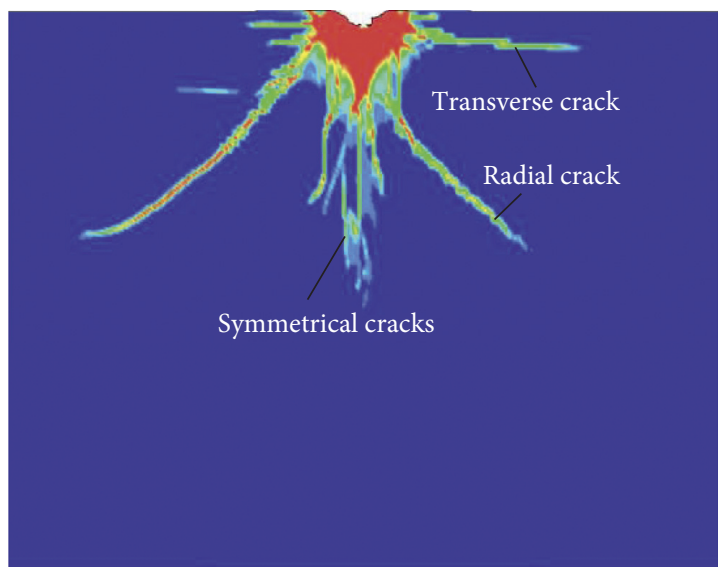

(c)

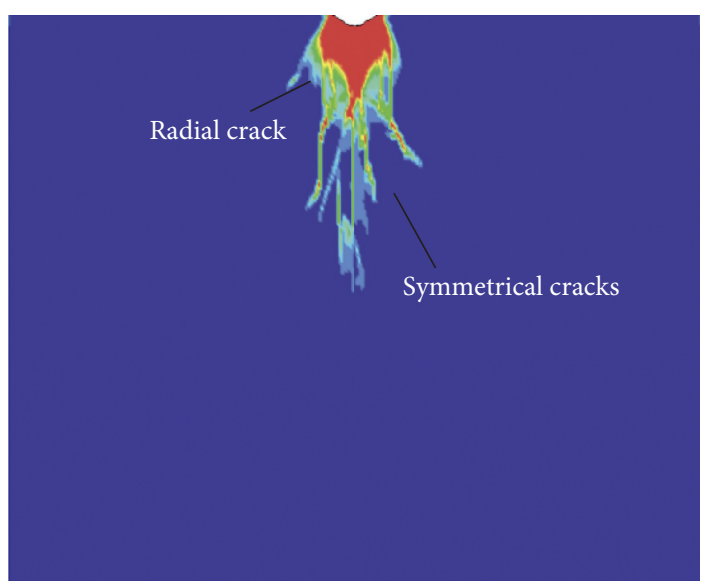

(b)

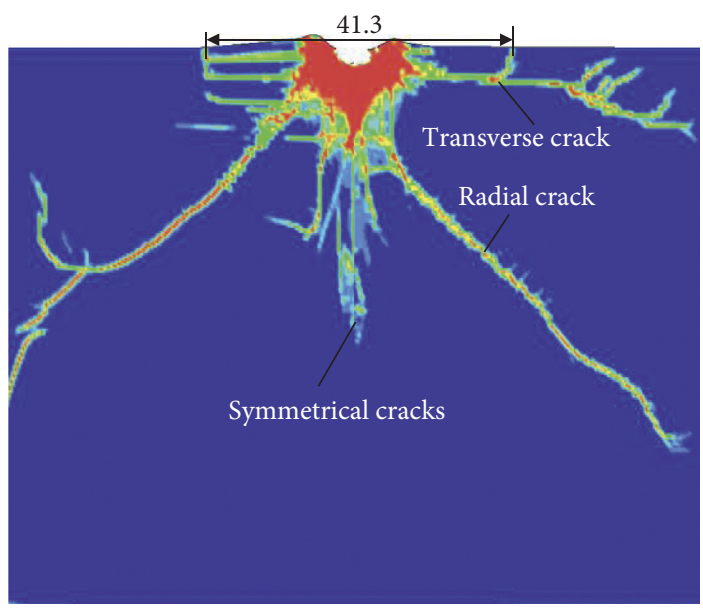

(d)

FIGURE 6: Rock breakage statuses at different times by the hemispherical indenter impact. (a) $0.35 \mu \mathrm{s}$. (b) $0.73 \mu \mathrm{s}$. (c) $1.9 \mu \mathrm{s}$. (d) $3.8 \mu \mathrm{s}$.

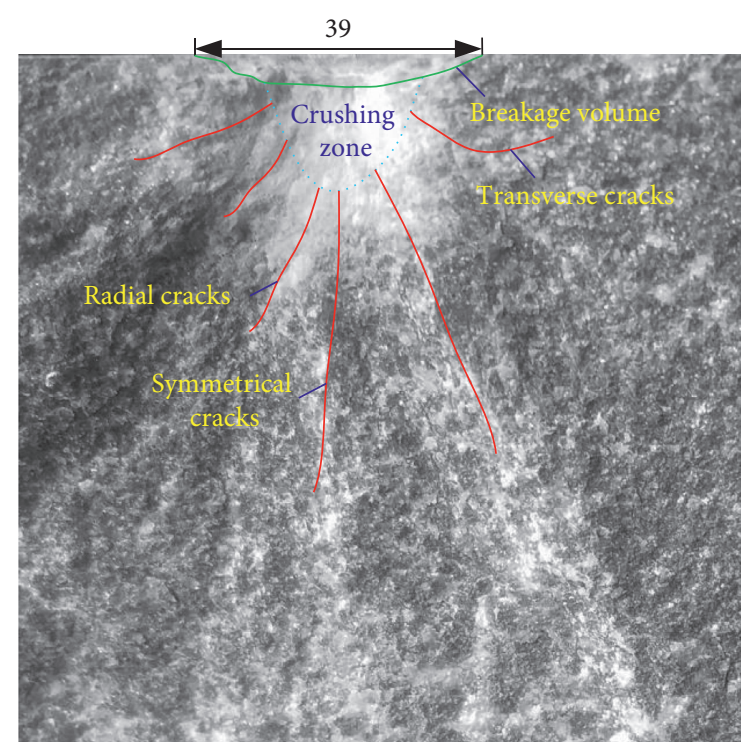

FIGURE 7: Crushing zone and crack distribution of the experimental rock breakage. rock breakage depth increases with the increase in the impact energy, and the increasing rates are all similar for different indenter types. In contrast to the rock breakage volume, the rock breakage depth by means of the cuspconical indenter is larger than that of warhead shape indenter within the scope of the impact energy in these experiments. According to the indenter shapes shown in Figure 2, the order of the curvature radius of the indenter tip is cusp-conical, warhead, hemispherical, spherical-arc, and then flat-top shape from the lowest to highest. Thus, we can conclude that the rock breakage depth is closely related to the curvature radius of the indenter tip because the conical shape is more likely to penetrate into the rock with a larger contact pressure [35]. Generally, the maximum stress of the rock caused by the indenter impact with a small curvature radius is larger than that of the indenter impact with a large curvature radius, and the stress acting on rock is not enough to break the hard rock when the curvature radius of the indenter exceeds a critical value. This is why the rock breakage depth is almost equal to 0 when the flat-top indenter is adopted in the rock breakage experiments as shown in Figure 9(e), and the breakage depth is still small with a 


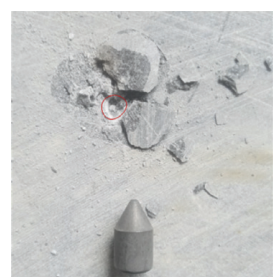

(a)

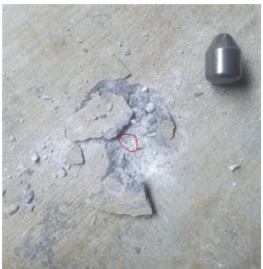

(b)

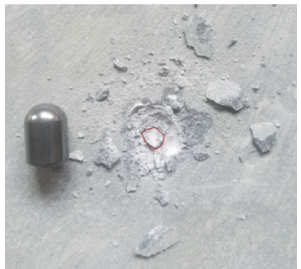

(c)

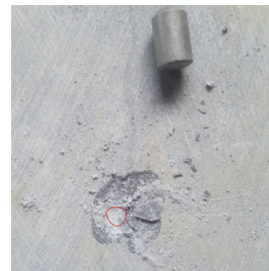

(d)

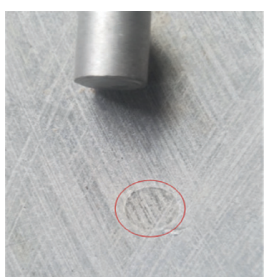

(e)

FIGURE 8: Rock fragmentation under different indenter shapes: (a) cusp-conical, (b) warhead, (c) hemispherical, (d) spherical-arc, and (e) flat-top.

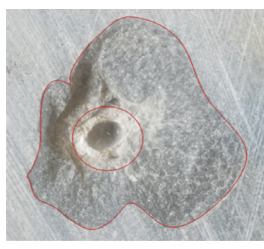

(a)

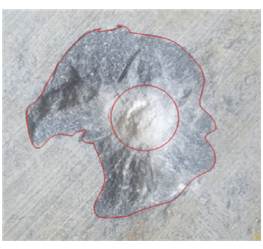

(b)

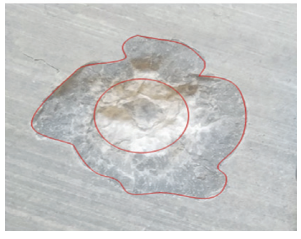

(c)

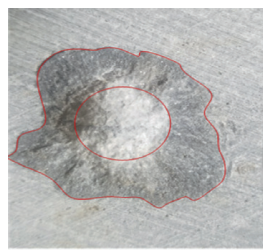

(d)

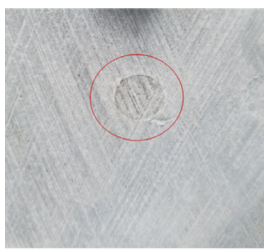

(e)

FiguRE 9: Rock breakage extent under different indenter shapes: (a) cusp-conical, (b) warhead, (c) hemispherical, (d) spherical-arc, and (e) flat-top.

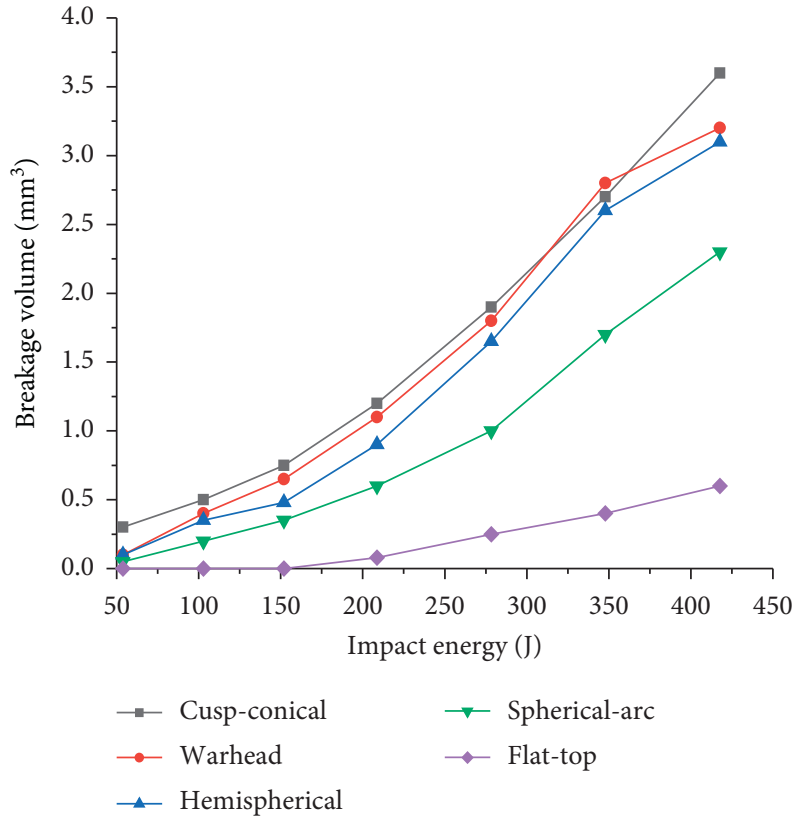

FIGURE 10: Rock breakage volume.

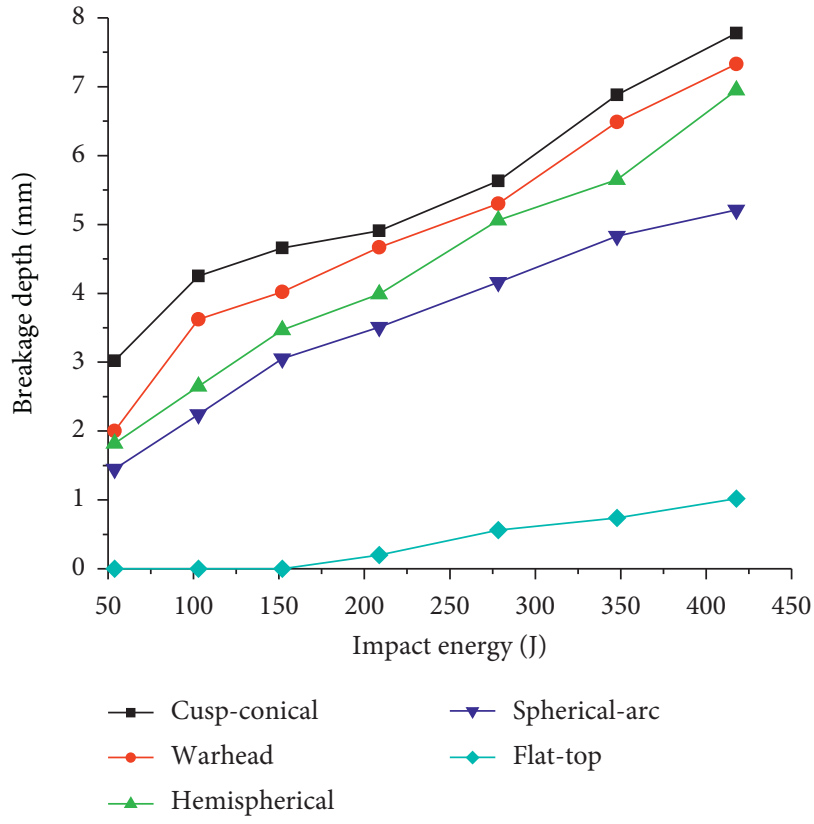

FIgURE 11: Rock breakage depth. considerable impact energy over $400 \mathrm{~J}$, as shown in Figure 11.

The approximate diameter of the rock breakage by different indenter shapes can provide a basis for rock breakage by multi-indenter impacts; thus, it is necessary to investigate the effect of the indenter shapes and impact energy on the rock breakage diameter. With the measurement method shown in Figure 4, the rock fragmentation of the diameters is shown in Figure 12, and it is evident that the rock breakage diameter enlarges with increasing impact energy, similar to the rock breakage volume and depth.
Dissimilarly, the rock breakage diameter by the indenter with a hemispherical shape is larger than that of the othershaped indenters. According to the interaction mechanics between the hemispherical indenter and rock, the deformed region dramatically increases with the penetration depth of the hemispherical indenter tip compared to that of the other indenter shapes, and thus a larger zone will potentially be broken. This is why the rock fracture area caused by the hemispherical indenter is the largest; however, the rock breakage diameters by the cusp-conical and warhead indenters are close to those of the hemispherical indenter 


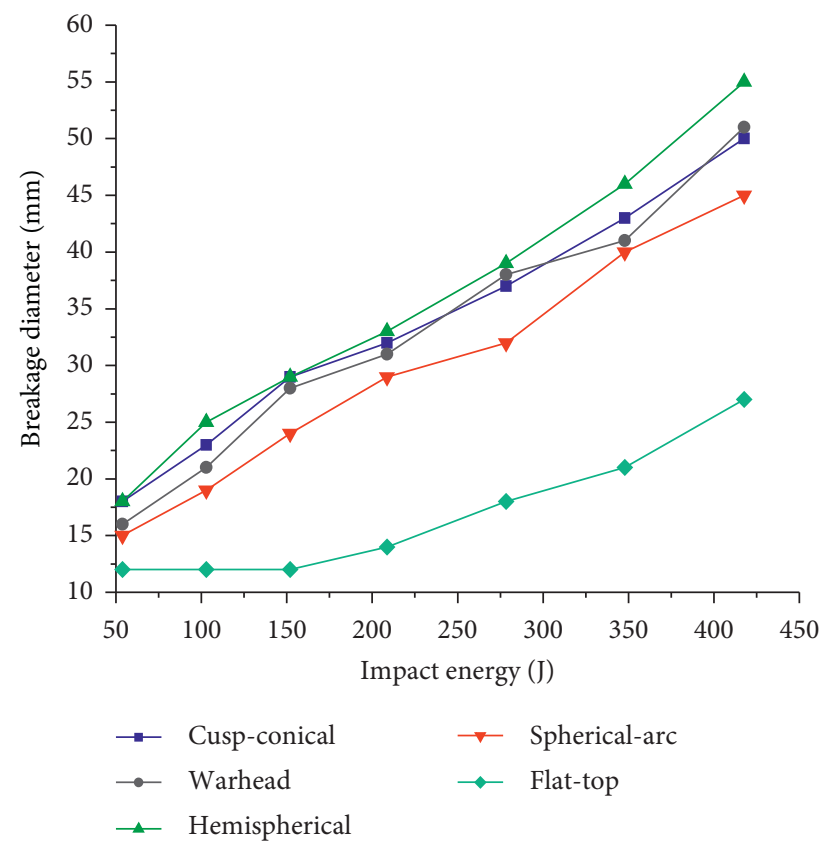

FIGURE 12: Rock breakage diameter.

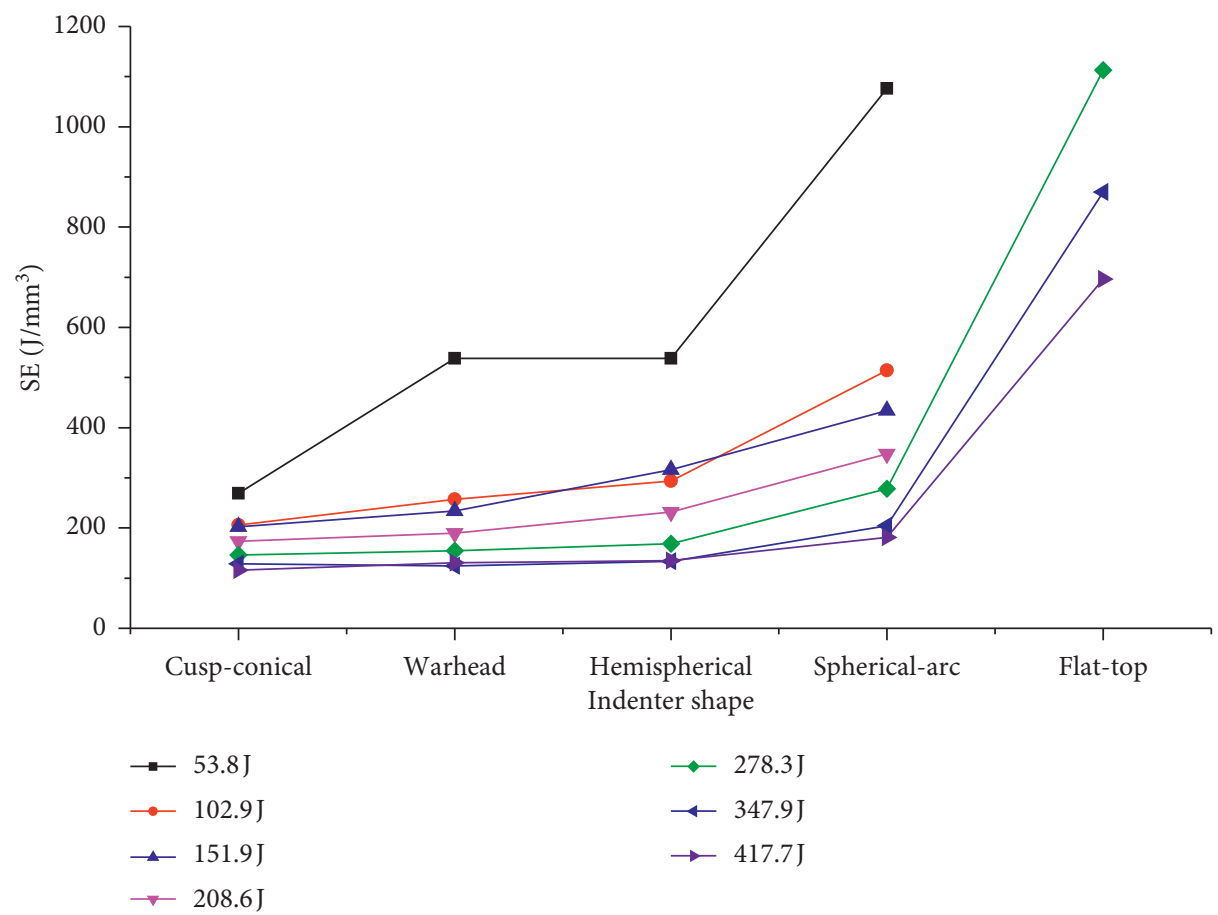

FIgURE 13: Specific energy consumption.

under different impact energies. As mentioned above, the rock breakage diameter is an important parameter for designing bits with multiple indenters [36-38]; thus, the preferred order of indenter shapes for hard rocks is the hemispherical, cusp-conical or warhead, spherical-arc, and flat-top shape.

Although the rock breakage volume, depth, and diameter are important for estimating the rock fragmentation performance, the specific energy consumption is a comprehensive index for evaluating the rock fragmentation ability of mechanical tools, such as a conical pick, drag pick, and disc cutter [39, 40]. According to (1), the specific energy consumption of the rock breakage by different indenter shapes and impact energies is shown in Figure 13. With the same impact energy, there is a large difference among the specific energy consumption of the rock breakage by 
different indenter shapes. When the impact energy is equal to $53.8 \mathrm{~J}$, the specific energy consumption of the indenter shapes is high except for the specific energy consumption of the cusp-conical indenter. This is because the rock stress caused by the indenter impact is not sufficient to break the hard rock when the curvature radius is not sufficiently small, and the rock breakage volume of the flat-top indenter is equal to 0 , especially. Therefore, a flat-top indenter is not recommended for hard rock breakage with a small impact energy, and the cusp-conical indenter is optimized by considering the rock breakage performance. From the view of specific energy consumption, the optimal energy consumption tool is cusp-conical shape for rock breakage by indenter impact because the specific energy consumption is the lowest compared to that of the other shapes. The rock can be broken by the spherical-arc indenter with an impact energy in the range of $53.8 \mathrm{~J}-417.7 \mathrm{~J}$, but the specific energy consumption is relatively large under a small impact energy. Therefore, the spherical-arc indenter is also not suggested for hard rock breakage in most cases, but it can be used for rock breakage with a large impact energy. This is because the specific energy consumption of the spherical-arc indenter is close to the hemispherical indenter when the impact energy reaches $417.7 \mathrm{~J}$ as shown in Figure 13. In addition, the specific energy consumption for the cusp-conical, warhead, and hemispherical indenters is nearly equal when the impact energy exceeds $347.9 \mathrm{~J}$; thus, the selection of the indenter shape should consider its structure and abrasive resistance, rather than the rock breakage volume, diameter, and specific energy consumption when a large impact energy is introduced. To obtain a lower specific energy consumption of the rock fragmentation, a larger impact energy is better for any indenter shape; thus, the impact energy is a key factor for rock breakage by means of indenter impact.

According to the above analysis of the rock breakage volume, depth, and specific energy consumption, we can consider that the cusp-conical indenter is better than the other shapes under the same impact energy. However, we realize that the cusp-conical indenter is more likely to be broken in hard rock fragmentation when the indenter is used repeatedly, as shown in Figure 14, which will present a short service life. Although the comprehensive rock breakage performance of the warhead and hemispherical indenter is slightly worse than that of the cusp-conical indenter, their contact stress is more appropriate for good durability. Therefore, due to the overall consideration of the rock breakage performance and indenter durability, the warhead and hemispherical indenters are preferred for hard rock fragmentation.

4.3. Different Impact Velocities and Energies. Thus far, the effect of the impact velocity on the rock breakage performance with the same impact energy is not clear, and therefore, the warhead and hemispherical indenters are adopted to carry out the rock breakage according to the above analysis. When the impact energy is equal to $208 \mathrm{~J}$, the rock breakage volume, diameter, and specific energy consumption with different impact velocities are obtained from

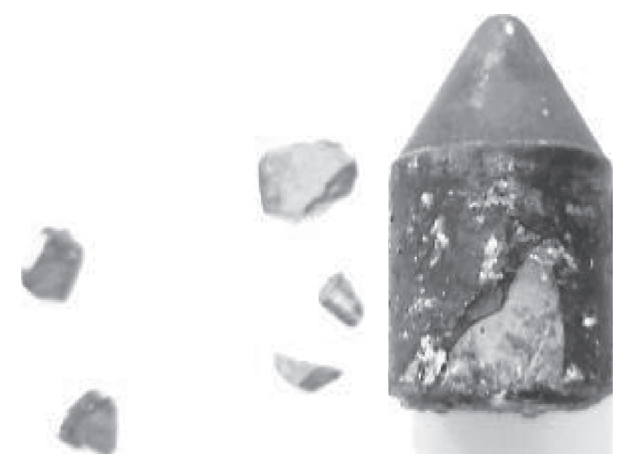

FIgURE 14: Failed cusp-conical indenter.

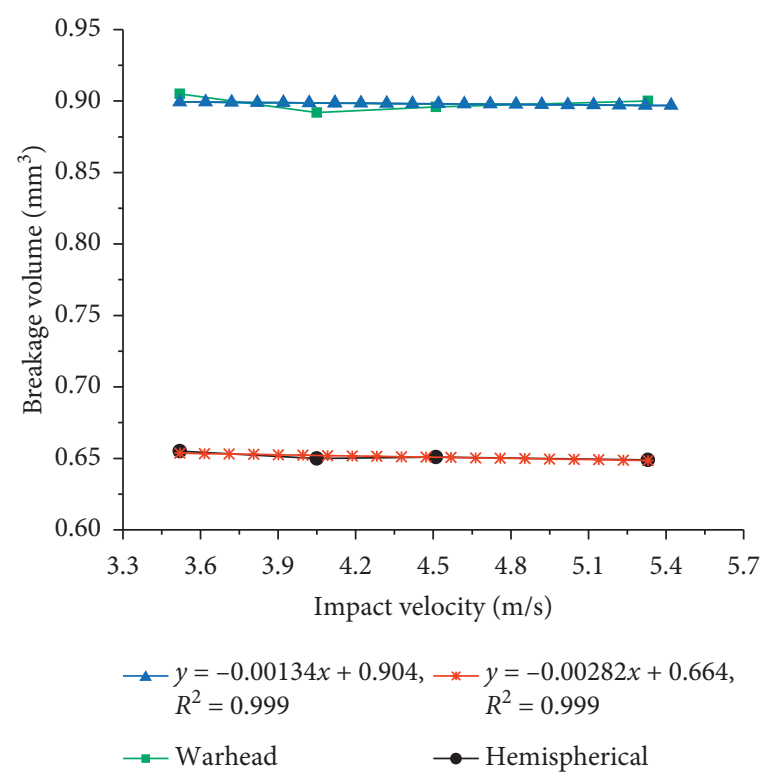

FIGURE 15: Rock breakage volume versus impact velocity.

the experiments, and the rock breakage volume and diameter versus the impact velocity are shown in Figures 15 and 16. Whether the indenter shape is a warhead or hemispherical shape, the effect of the impact velocity on the rock breakage volume, diameter, and specific energy consumption is ideal when the final velocity of the impact hammer is in the range between $3.52 \mathrm{~m} / \mathrm{s}$ and $5.33 \mathrm{~m} / \mathrm{s}$. The least squares method is adopted to conduct a linear regression on the test results. By means of the warhead and hemispherical indenters, the linear regression coefficients of the rock breakage volume and diameter versus the impact velocity are all approximately equal to 1 , and the slopes of these regression equations are in the range of $0.001-0.04$, as shown in Figures 15 and 16. It can be seen that the linear regression method is correct and reliable for fitting the relationship between the rock breakage, diameter, and impact velocity when the impact energy is constant. The fitting line is approximately parallel to the abscissa axis, which shows that the rock breakage volume and diameter by means of the warhead and hemispherical indenters are not related to the impact velocity. Thus, the impact velocity is negligible 


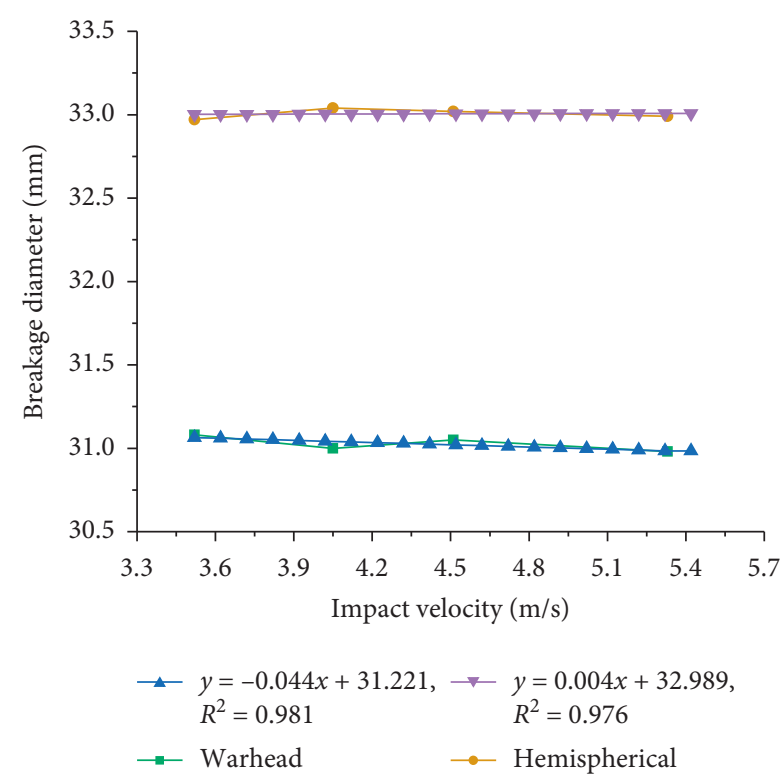

FIGURE 16: Rock breakage volume versus impact velocity.

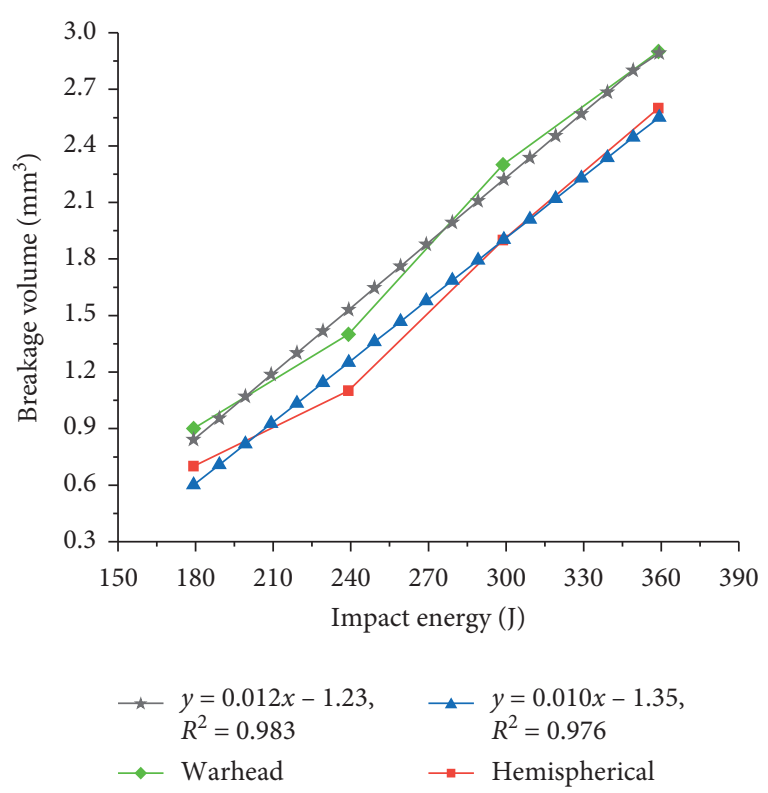

FIgURE 17: Rock breakage volume versus impact energy.

in the design of the rock fragmentation by indenter impact within the velocity scope in this paper.

It is not clear if the effect of the impact energy on the rock breakage performance under indenter impact will impact velocity in the same way. When the impact velocity is equal to $4.94 \mathrm{~m} / \mathrm{s}$, the breakage volume and specific energy consumption versus the impact energy are shown in Figures 17 and 18. Unlike the effect of the impact velocity on the rock breakage performance, the impact energy has a large influence on the rock breakage performance under the same impact velocity. Whether the indenter shape is a warhead or hemispherical shape, the breakage volume and specific energy

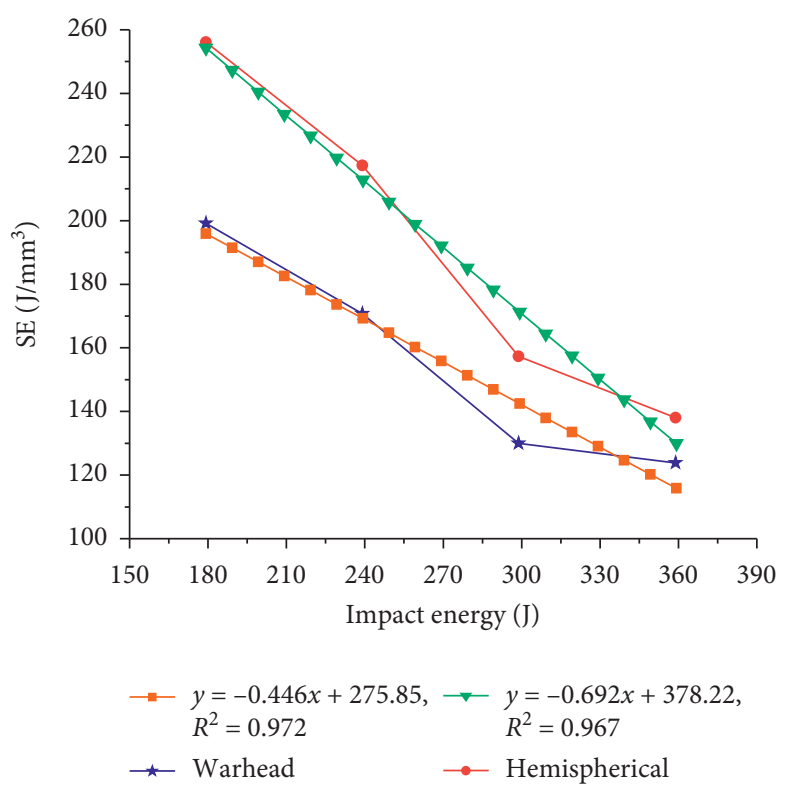

Figure 18: SE versus impact energy.

consumption all increase with increasing impact energy. Thus, we can conclude that the impact energy plays a decisive role in rock breakage rather than the impact velocity.

\section{Conclusions}

In the present study, a test bed for rock fragmentation by indenter impact was developed to obtain the rock breakage volume, depth, and area under different impact conditions, and a numerical simulation was used to investigate the rock breakage process. The effect of indenter shape, impact energy, and impact velocity on the rock breakage performance was investigated. From the experimental and numerical results, we come to the following conclusions:

(1) The rock breakage modes at the upper and lower part of the rock from the numerical simulation are consistent with those in the experiment. The hard rock near the indenter impact point is severely crushed due to the extremely high local pressure at the initial impact stage, and a centerline crack is formed perpendicular to the bottom in the rock interior due to the rock continuity and isotropy. Many radical cracks appear around the crushing zone, and some of them intersect with the top surface of rock, resulting in large rock debris formation.

(2) With identical indenter shape and impact velocity, the rock breakage volume, depth, and area all increase with impact energy, and the impact energy plays a decisive role in rock breakage in this condition. The indenter shape has a greater influence on the rock breakage performance than that of the impact velocity with the same impact energy, and the effect of the impact velocity on the rock breakage performance could be ignored under the condition of the same impact energy. 
(3) For the lowest to highest specific energy consumption, the order of indenter shapes is cusp-conical, warhead, hemispherical, spherical arc, and flat-top under the same impact energy and velocity, but damage occurs in the cusp-conical indenter after several impacts. Considering that the rock breakage difference among the indenter shapes of cusp-conical, warhead, and hemispherical under high impact energy is minimal, the warhead and hemispherical indenters are preferred for hard rock breakage.

\section{Data Availability}

The raw data used to support the findings of this study have not been made available because the data also form a part of an ongoing study.

\section{Conflicts of Interest}

The authors declare that they have no conflicts of interest.

\section{Acknowledgments}

This study was funded by the Fundamental Research Funds for the Central Universities (2018QNB07) and the Priority Academic Program Development of Jiangsu Higher Education Institute of China (PAPD).

\section{References}

[1] X. Wang, Y. Liang, Q. Wang, and Z. Zhang, "Empirical models for tool forces prediction of drag-typed picks based on principal component regression and ridge regression methods," Tunnelling and Underground Space Technology, vol. 62, pp. 75-95, 2017.

[2] X. Liu, S. Liu, and H. Ji, "Numerical research on rock breaking performance of water jet based on SPH," Powder Technology, vol. 286, pp. 181-192, 2015.

[3] D. Yang, J. Li, L. Wang, K. Gao, Y. Tang, and Y. Wang, "Experimental and theoretical design for decreasing wear in conical picks in rotation-drilling cutting process," The International Journal of Advanced Manufacturing Technology, vol. 77, no. 9-12, pp. 1571-1579, 2015.

[4] O. Su and N. Ali Akcin, "Numerical simulation of rock cutting using the discrete element method," International Journal of Rock Mechanics and Mining Sciences, vol. 48, no. 3, pp. 434-442, 2011.

[5] M. Saadati, P. Forquin, K. Weddfelt, P.-L. Larsson, and F. Hild, "A numerical study of the influence from pre-existing cracks on granite rock fragmentation at percussive drilling," International Journal for Numerical and Analytical Methods in Geomechanics, vol. 39, no. 5, pp. 558-570, 2015.

[6] T. Saksala, M. Fourmeau, P.-A. Kane, and M. Hokka, "3D finite elements modelling of percussive rock drilling: estimation of rate of penetration based on multiple impact simulations with a commercial drill bit," Computers and Geotechnics, vol. 99, pp. 55-63, 2018.

[7] H. Y. Liu, S. Q. Kou, P.-A. Lindqvist, and C. A. Tang, "Numerical simulation of the rock fragmentation process induced by indenters," International Journal of Rock Mechanics and Mining Sciences, vol. 39, no. 4, pp. 491-505, 2002.
[8] S. Q. Kou, H. Y. Liu, P.-A. Lindqvist, and C. A. Tang, "Rock fragmentation mechanisms induced by a drill bit," International Journal of Rock Mechanics and Mining Sciences, vol. 41, no. supplmentary 1, pp. 527-532, 2004.

[9] H. Y. Liu, S. Q. Kou, and P. A. Lindqvist, "Numerical studies on bit-rock fragmentation mechanisms," International Journal of Geomechanics, vol. 8, no. 1, pp. 45-67, 2008.

[10] H. Huang and E. Detournay, "Intrinsic length scales in toolrock interaction," International Journal of Geomechanics, vol. 8, no. 1, pp. 39-44, 2008.

[11] T. Saksala, "3D numerical modelling of bit-rock fracture mechanisms in percussive drilling with a multiple-button bit," International Journal for Numerical and Analytical Methods in Geomechanics, vol. 37, no. 3, pp. 309-324, 2012.

[12] T. Saksala, D. Gomon, M. Hokka, and V.-T. Kuokkala, "Numerical and experimental study of percussive drilling with a triple-button bit on Kuru granite," International Journal of Impact Engineering, vol. 72, pp. 56-66, 2014.

[13] T. Saksala, "Numerical study of the influence of hydrostatic and confining pressure on percussive drilling of hard rock," Computers and Geotechnics, vol. 76, pp. 120-128, 2016.

[14] K. Hashiba, K. Fukui, Y. Z. Liang, M. Koizumi, and T. Matsuda, "Force-penetration curves of a button bit generated during impact penetration into rock," International Journal of Impact Engineering, vol. 85, pp. 45-56, 2015.

[15] B. Lundberg and P. Collet, "Optimal wave shape with respect to efficiency in percussive drilling with detachable drill bit," International Journal of Impact Engineering, vol. 86, pp. 179-187, 2015.

[16] M. Fourmeau, A. Kane, and M. Hokka, "Experimental and numerical study of drill bit drop tests on Kuru granite," Philosophical Transactions of the Royal Society A: Mathematical, Physical and Engineering Sciences, vol. 375, no. 2085, Article ID 20160176, 2017.

[17] S. Aziznejad, K. Esmaieli, J. Hadjigeorgiou, and D. Labrie, "Responses of jointed rock masses subjected to impact loading," Journal of Rock Mechanics and Geotechnical Engineering, vol. 10, no. 4, pp. 16-26, 2018.

[18] N. Cinca, B. D. Beake, A. J. Harris, and E. Tarrés, "Micro-scale impact testing on cemented carbides," International Journal of Refractory Metals and Hard Materials, vol. 84, Article ID 105045, 2019.

[19] X. M. Liu, H. B. Wang, X. Y. Song, and Q. W. Zhang, "Indentation-induced deformation of ultracoarse grained cemented Carbides," in Proceedings of the European Congress and Exhibition on Powder Metallurgy, European Powder Metallurgy Association, Hamburg, Germany, pp. 1-6, Octobar 2016.

[20] O. Su, "Performance evaluation of button bits in coal measure rocks by using multiple regression analyses," Rock Mechanics and Rock Engineering, vol. 49, no. 2, pp. 541-553, 2016.

[21] Q. Geng, Z. Y. Wei, and H. Meng, "An experimental research on the rock cutting process of the gage cutters for rock tunnel boring machine (TBM)," Tunnelling and Underground Space Technology, vol. 52, pp. 182-191, 2016.

[22] C. Wang, Y. Lu, G. Hao, B. Cui, and Z. Zhao, "Simulated test on compression deformation characteristics and mechanism of fractured rock in mined out area," Geotechnical and Geological Engineering, vol. 36, no. 5, pp. 2809-2821, 2018.

[23] Q. L. Zeng, Z. W. Wang, L. R. Wan, X. Zhang, and Z. G. Lu, "Study on the damage of coal and rock with diamond saw blade cutting based on LS-DYNA," International Journal of Computational Materials Science and Engineering, vol. 6, no. 4, Article ID 1750026, 2017. 
[24] C. Grunwald, B. Schaufelberger, A. Stolz, W. Riedel, and T. Borrvall, "A general concrete model in hydrocodes: verification and validation of the Riedel-Hiermaier-Thoma model in LS-DYNA," International Journal of Protective Structures, vol. 8, no. 1, pp. 58-85, 2017.

[25] L. B. Jayasinghe, J. Shang, Z. Zhao, and A. T. C. Goh, "Numerical investigation into the blasting-induced damage characteristics of rocks considering the role of in-situ stresses and discontinuity persistence," Computers and Geotechnics, vol. 116, Article ID 103207, 2019.

[26] H. X. Jiang, C. L. Du, S. Y. Liu, and K. D. Gao, "Numerical simulation of rock fragmentation under the impact load of water jet," Shock and Vibration, vol. 2014, Article ID 219489, 11 pages, 2014.

[27] I. Nishioka, M. Funaki, and T. Sekine, "Shock-induced anisotropy of magnetic susceptibility: impact experiment on basaltic andesite," Earth, Planets and Space, vol. 59, no. 11, pp. e45-e48, 2007.

[28] H. A. Ai and T. J. Ahrens, "Simulation of dynamic response of granite: a numerical approach of shock-induced damage beneath impact craters," International Journal of Impact Engineering, vol. 33, no. 1-12, pp. 1-10, 2007.

[29] S. Widjaja, J. E. Ritter, and K. Jakus, "Influence ofR-curve behaviour on strength degradation due to Hertzian indentation," Journal of Materials Science, vol. 31, no. 9, pp. 2379-2384, 1996.

[30] H.-x. Jiang, C.-l. Du, and Z.-h. Liu, "Theoretical and numerical investigation on rock fragmentation under highpressure water-jet impact," Iranian Journal of Science and Technology, Transactions of Civil Engineering, vol. 41, no. 3, pp. 305-315, 2017.

[31] Z. Zhu, B. Mohanty, and H. Xie, "Numerical investigation of blasting-induced crack initiation and propagation in rocks," International Journal of Rock Mechanics and Mining Sciences, vol. 44, no. 3, pp. 412-424, 2007.

[32] M. M. D. Banadaki and B. Mohanty, "Numerical simulation of stress wave induced fractures in rock," International Journal of Impact Engineering, vol. 40-41, pp. 16-25, 2012.

[33] S. Grange, P. Forquin, S. Mencacci, and F. Hild, "On the dynamic fragmentation of two limestones using edge-on impact tests," International Journal of Impact Engineering, vol. 35, no. 9, pp. 977-991, 2008.

[34] M. Cai and P. K. Kaiser, "Numerical simulation of the Brazilian test and the tensile strength of anisotropic rocks and rocks with pre-existing cracks," International Journal of Rock Mechanics and Mining Sciences, vol. 41, no. 3, pp. 478-483, 2004.

[35] C. E. Truman, A. Sackfield, and D. A. Hills, "Contact mechanics of wedge and cone indenters," International Journal of Mechanical Sciences, vol. 37, no. 3, pp. 261-275, 1995.

[36] S. Liu, H. Chang, H. Li, and G. Cheng, "Numerical and experimental investigation of the impact fragmentation of bluestone using multi-type bits," International Journal of Rock Mechanics and Mining Sciences, vol. 91, pp. 18-28, 2017.

[37] K.-B. Kwon, C.-H. Song, J.-Y. Park, J.-Y. Oh, J.-W. Lee, and J.-W. Cho, "Evaluation of drilling efficiency by percussion testing of a drill bit with new button arrangement," International Journal of Precision Engineering and Manufacturing, vol. 15, no. 6, pp. 1063-1068, 2014.

[38] H. Kang, J.-Y. Park, J.-W. Cho, J.-S. Jang, K.-W. Kim, and J.-W. Lee, "Optimal button arrangement of a percussion drill bit and its operating condition for improving drilling efficiency," Proceedings of the Institution of Mechanical Engineers, Part C: Journal of Mechanical Engineering Science, vol. 232, no. 16, pp. 2887-2898, 2018.
[39] H. Kang, J.-W. Cho, J.-Y. Park et al., "A new linear cutting machine for assessing the rock-cutting performance of a pick cutter," International Journal of Rock Mechanics and Mining Sciences, vol. 88, pp. 129-136, 2016.

[40] Y.-D. Xue, F. Zhao, H.-X. Zhao, X. Li, and Z.-X. Diao, “A new method for selecting hard rock TBM tunnelling parameters using optimum energy: a case study," Tunnelling and Underground Space Technology, vol. 78, pp. 64-75, 2018. 